\title{
Public trust in policing: A global search for the genetic code to inform policy and practice in Canada
}

\author{
Marnie Clark, ${ }^{*}$ Rebecca Davidson, ${ }^{\dagger}$ Vanessa Hanrahan ${ }^{\ddagger} \&$ Norman E. Taylor ${ }^{\S}$
}

\begin{abstract}
The Executive Global Studies Program is an experiential and research-driven learning model for succession-ready police leaders and related executives across Canada, operating since 2003. Its research themes for each cohort are assigned by the Canadian Association of Chiefs of Police (CACP). Nominees are each named and funded by their respective agencies with a view to informing domestic public policy and practice, while also providing a developmental framework for building global networks, shared geo-political awareness, and advanced executive competencies among the police leadership community. The program's tenth cohort completed a 15-country study on the subject of public trust in policing, and they recently presented their summarized research results to the CACP for consideration and action. In this paper, these results are summarized and discussed for their potential implications for policy, practice, and continuing study. The primary focus of these authors, all of whom are Global 2017 team members, is to trace and explain the qualitative research process applied by their full cohort as they uncovered and conceived what the team ultimately characterized as 'the genetic code of public trust', a new grounded theory meant to inform and guide those continuing policy and practice considerations in Canada and beyond.
\end{abstract}

Key Words Policing; community relations; public trust; police legitimacy; community safety and well-being

Journal of CSWB. 2017 Dec;2(3):101-111

www.journalcswb.ca

\section{INTRODUCTION}

The trust of the public is extremely important to any model of policing that purports to be founded on democratic principles, and most notably, under Canada's long-expressed commitment to policing with the consent of the people. Simply put, in policing, perhaps more so than in any other public service, trust matters. Thus, the Canadian Association of Chiefs of Police (CACP) Board of Directors assigned public trust as a research project to be completed by the 2017 cohort in the CACP Executive Global Studies program. CACP Global Studies is a unique professional development program for executives from policing and related public safety and criminal justice agencies. The program spans over six months of intense study and collaboration, and it applies a researchdriven and problem-based learning model. The 2017 cohort was challenged to examine public trust domestically and around the world, leading them to conduct field studies in 15 countries, ranging from environments where trust in the police was perceived to be very low, to those with enviable trust indicators on recognized scales of public opinion. The team also examined and considered information from the
United States and Canada, and the 20 members engaged in extensive discussions and debates on the elements of public trust, based upon their own experiences in 13 different Canadian agencies. The specific charge to the team from the CACP was as follows:

\section{Measuring and Responding to New Dimensions of Public Trust \& Confidence: \\ CACP Global 2017 will be challenged, through domestic and international studies, to isolate a new set of dimensions that will best define and/or influ- ence public trust and confidence today and into the future, to produce new methods for more accurately measuring against those dimensions in Canadian communities, and where indicated, to propose new strategies for aligning our police policies and prac- tices to meet evolving public expectations.}

A full-team synthesis followed from preparatory domestic studies and multiple sub-team field studies around the globe. One thing discovered very clearly by the research team is that there are no universally accepted methodologies 
to measure or respond to trust, nor even any that could be deemed to be best practices. It seems societies everywhere are still grappling with this question (CACP Global, 2017a). Also learned by all sub-teams was that Canadian policing is very well respected and often envied around the world and, in this regard, Canada is doing many things right.

Yet to ensure public trust continues, the team's research results also argue strongly that there may be an urgent need for a re-orientation of Canadian thinking on matters of public trust. The results discussed below call for the application of new approaches taken together with our communities, and for continuous and more dynamic measurement of mutual trust informed by multiple perspectives, including those of diverse community members in each and every policing jurisdiction throughout the country.

\section{METHODS}

\section{Research Model and Ethical Considerations}

CACP Global Studies is built on an adult learning foundation that draws heavily on constructivist principles, and a design model that seeks to generate a transformative learning experience for its members (CACP 2006). For such to occur, the 'messy problem' that drives the experience must be one that is both genuine and urgent (Mezirow, 1991). At the same time, the bounded nature of the program limits the available time and resources available to each cohort. As a result, CACP Global Studies has favoured qualitative (QL) forms of research as the preferred vehicle for achieving the desired developmental outcomes. Three key aspects of QL research methods are particularly relevant here.

First, because in QL research the researchers and their personal knowledge and perspectives become an integral part of the research itself, the disciplines associated with bracketing and self-awareness can be valuable tools, important to the transformative impact of the experience (Neuman, 2006; Cresswell, 2009). As a result, much of the formative work behind the field studies is designed to elicit and examine preexisting biases and assumptions among the members, all of whom have years of immersion in a policing culture and most of whom have held positions of increasing executive responsibility. The assistance of objective academic and practice-based research coaches and extensive literature reviews, guided the development of the research lens and helped to establish an appropriate ethical framework around the entire study (Lawrence, 2017; Maguire, 2017; Valcour, 2017; presentations to CACP Executive Global Studies Program, February 2017).

Secondly, the QL concepts of interpretive inquiry are often new to members of the Global Studies cohorts. This means that new skills need to be learned and practiced before embarking on worldwide field encounters. Global Studies obtained the cooperation of several representatives of locally diverse communities to provide both the necessary preparation and practice opportunities; these representatives were a powerful source of relevant domestic research on the topic, as well.

Thirdly, as is central to such forms of inquiry, a clear mental model needed to be formed and collectively understood, such that field data could be captured by all sub-teams with authenticity and later synthesized by the full team to reveal some level of grounded theory and/or other practical outcomes (Neuman, 2006).
During these initial efforts, achieving a common understanding of the assigned research theme proved to be more challenging than expected. After careful consideration, and based on inputs from academic and practical expert sources, it was determined that the assigned statement "public trust and confidence in the police" needed some refinement, with the team ultimately concluding that the term "confidence" is either a synonym or an antecedent of trust, and therefore was not required within their final research statement.

Following a detailed analysis of the subject matter, a concise research statement was fashioned by the team with the help of their research coaches, to provide consistency to the field research to be conducted by the five sub-teams, each of whom would travel to three countries to complete their studies among a range of interview subjects.

\section{Global Studies 2017 Research Statement}

Policing with consent requires mutual trust with the diverse communities we serve. CACP Global Studies 2017 will pursue an international comparative study to examine the relational and internal dimensions that influence public trust. Our goal is to identify measures and responses that will inform Canadian public policy and policing practices.

With the research statement firmly defined, the team further prepared to embark upon the field phase of the study equipped with common, guiding dimensions to assist in the framing of the studies and to shape the later synthesis of observations and data derived from across the five study teams. These dimensions were determined through extensive analysis of the literature and the other expert inputs made available to the team through their preparatory studies. Essentially, on the consensus of the team, these dimensions capture the trust-influencing factors that are operating to varying degrees in the full context that shape and guide policing and its relationship with the public and other state and non-state actors, in any national or local environment. See Appendix A for greater detail on the sub-elements that further inform each dimension.

\section{Global Studies 2017 Research Dimensions}

- Sociopolitical: social, economic, and political context that defines, shapes, and influences the demands made upon police

- Policing Framework: structure underlying the delivery of policing services and programs

- Information Management: discipline that directs, supports, and effectively and efficiently shares and manages data and metrics

- Engagement/Communication: clear, consistent messaging of pertinent information via a variety of methods; the interactions, behaviours, and relationships that encourage participation/ collaboration

- Professionalism \& Competence: organizational values, specialized knowledge, attitudes, skills, and abilities associated with policing

- Accountability: responsibility for actions, outcomes, decisions, and policies 


\section{Literature Review}

An extensive review of the extant trust literature was conducted to inform the team's understanding of (1) determinants of trust and overall trust levels across macro social institutions; and, (2) trust in policing and country-specific case studies. The following offers a brief summary, highlighting just some of the team's early findings in each of these streams of the research.

\section{Trust in Public Institutions}

Research has established that "trust underpins all human and institutional interactions" and without trust, policychange and the delivery of service to citizens is compromised (Tonkiss, Passey, Fenton et al., 2000; Misztal, 1996). The determinants of trust with the public (Brecher \& Flynn, 2002, Latusek \& Olejniczak, 2016) have been conceptualized and operationalized differently across many sectors, including government (Blind, 2007; OECD, 2017), health care (Kalra, Unnikrishnan, \& Baruah, 2017), and the military (Kasher, 2003) and the following common themes emerge as being key: communication, transparency, regulations/standards, accountability, and competence.

Studies show that trust in government has been declining since the mid-1960s in advanced democratic societies (Tonkiss et al., 1996). While the pattern and pace of this decline in trust varies across countries, political unrest, economic downturns, and corruption scandals have all identified as contributing factors to this decrease. The Edelman World Trust Barometer (Edelman Trust Barometer, 2017) tracks trust across four institutions: government, business, media, and non-governmental organizations (NGOs), and 2017 results showed significant declines in trust levels across these sectors. The erosion of trust was linked to continued globalization, economic downturn, erosion of values, and lack of leadership. Edelman offered the following advice to improve trust in the business sector, but it can be also be applied to other institutions:

“... communicate frequently with honesty; take responsibility for actions; put people ahead of profit; act transparently and openly; and embrace ethical business practices (Edelman, 2017).

Trust is not a static concept, as it can erode and at times it can be lost. As such, a review of the rebuilding trust literature was also conducted. The findings revealed the importance of relationship building, communication, and leadership (Awan, 2014; Kalra et al., 2017). Edelman's (2017) research went a step further and suggested rebuilding trust was tantamount to restoring faith in the system and required organizations to "step outside of their traditional roles and work toward a new, more integrated operating model that puts people-and the addressing of their fears - at the center of everything they do". Consistent throughout all this literature is the theme that organizations must actively engage in actions and relationships that foster, sustain, and promote trust.

\section{Trust in the Police}

The police-specific literature establishes the concept of "trust" as fundamental to establishing stability, integrity, and the effective delivery of services (Boda, 2017). Goldsmith's (2005) extensive review of police-trust literature concluded police trust depends upon a range of factors both within and outside police control that are reflective of the Global Studies dimensions discussed above. The works of Tyler and others on police legitimacy and procedural justice also cut across and informed virtually every dimension in the study (Murphy, Mazerolle \& Bennett, 2014; Sunshine \& Tyler, 2003).

Research into Malaysia and Indonesia, in particular, revealed many linkages to the team's Sociopolitical and Accountability dimensions. Although research indicated there was low public trust in many of the South East Asian countries studied, there had been concerted efforts in these countries to improve public trust in police. The importance of accountability, human rights, and independence from government was very clear in the research, and later confirmed in the field studies. As one example, Strengthening the Royal Malaysian Police by Enhancing Accountability (Chan, 2016) also considered the power of the Inspector General of Police and the slew of controversial legislative instruments that afford that office a great deal of latitude in choosing when and how to apply the laws. "This paper argues for the establishment of the Independent Police Complaints and Misconduct Commission [IPCMC] to receive, investigate and recommend a course of action for complaints about the Royal Malaysian Police [RMP]". A follow-up paper in October 2017 advocated for the decentralization of the National Police. Organizations such as the Malaysian Bar and Human Rights Commission of Malaysia [SUHAKAM] also have expressed concerns in accountability and human rights with regards to policing in that country.

Academics have recently explored factors that shape perceptions of trust and police legitimacy in Spain (Bradford, Martin, García-Añón et al., 2016) and found relational and expressive factors in relationships (e.g., quality of police behaviours) are more important than instrumental factors (e.g., enforcing the laws) for establishing police trust. Recent reports indicated despite record level unemployment rates, the crime rate there remained relatively stable (OSAC, 2016). This finding, coupled with the high-corruption rates among government, politicians, and royalty (The Local es, 2017), culminated in Spain being an intriguing country for the team to explore the effects of the Socio-Political dimension on policing.

Europe-related research informed the understanding of societies with higher trust levels and potentially best practices in conceptualizing and measuring police trust. Most of the selected countries in Europe have a mix of national, regional, and local police systems that are similar in concept and construct to those in Canada. In addition, most have experienced many of the same factors of globalization as Canada is now recognizing, including human migration, technological advancement, global organized crime and terrorism, and changing economic and trade patterns (CACP Global, 2016).

The Scandinavian countries, in particular, feature prominently in the literature for their higher reported levels of public trust, although officials there were, later, open in their own observations that the reality of those mutual trust relationships are being increasingly strained due to social changes, on the one hand, and may indeed be over-stated by the currently available measurement regimes, on the other. 


\section{Defining the Scope and Executing the Field Studies}

To add to the body of domestic and international knowledge the team had gained from the members' own backgrounds, from the team's literature review, and from many online and workshop-based deliberations, the team first tested their research model with members from the invited, domestic diverse community groups referenced above. These highly interactive discussions further developed the dimensions of trust, and helped the team to design specific field questions to later capture these attributes of trust in different global environments. These questions would later be applied in the field, through the conduct of interviews with a wide range of sources in each country selected for the study, including police, government, NGOs, local media, community activists, and members of the public at large. See Appendix B for a full outline of the common interview questions that guided the field studies of each sub-team.

The cohort also recognized that a collective understanding of policing in the United States as it pertains to public trust, and their access to rich sources of information through the International Association of Chiefs of Police (IACP) and other US collaborations, would also provide essential information for the overall study. Through many professional development opportunities and cross-border relations, the team was well positioned to include within the research an overarching appreciation of the dynamics of public trustand public mistrust-in the police from a US perspective.

Determining the global study sample was greatly assisted through the cooperation of the Royal Canadian Mounted Police (RCMP) International Policing Division, and specifically, the network of Liaison Officers located in regions around the globe. Having settled on a low-trust to high-trust rationale from their earlier deliberations on their mental model, and based on such considerations as time, budget, and safety, the team ultimately selected a total of 15 countries, configured into five logical travel plans. Each of the field studies spanned a period of 12-14 days, and each included upwards of 20 individual and formal group interviews.

Based on all of their preparatory research steps described above, the five research groups selected the following countries, clustered along a scale as determined from the available data, from apparent low-trust to high-trust public perceptions about policing.

Team Indonesia selected Malaysia, Singapore, and Indonesia (low-trust environments). Although research indicated there is low public trust, there have been concerted efforts in these countries to improve public trust in police. In 2005, the Indonesia National Police introduced a gradual reform program. "Most Indonesians still have little faith in the National Police - even though increasing public trust was one of its main reform goals. This lack of trust stems from, among other things, bad behavior by officers and media exposure of inappropriate and at times illegal conduct by both the institution and its personnel" (Hidayat, 2016). In addition, NGOs such as IDEAS [Institute for Democracy and Economic Affairs] had conducted research and had made strong recommendations for the policing sector. In 2005, there was a Royal Commission to Enhance the Operation and Management of the Royal Malaysia Police. The research team hoped to measure the successes and the barriers to increasing public trust and determine what dimensions had the most impact.
Team South East Asia selected Hong Kong, Thailand, and Vietnam (low-trust environments). One large survey in Thailand was conducted for the study "The Relationships Between Police Performance and Public Confidence: A Case Study of Thailand" (Sahapattanaa \& Cobkitb, 2016). The team was interested in comparing public trust across three countries, and analyzing the impact of the change in Hong Kong rule from the United Kingdom to the People's Republic of China. Vietnam represented the first fully communist regime to be visited by any Global Studies team since the program's inception in 2003.

Team Mediterranean selected Malta, Spain, and Gibraltar (medium-trust environments). Spain's stable police-trust results, despite economic and political turmoil, were of particular interest to the research team. By contrast, Malta and Gibraltar offered insight into unique, smaller jurisdictions. The expectation for Malta police has recently expanded to include crimes not typically investigated by police (e.g., domestic violence) and the team was interested in exploring the implications for police-community relations. Gibraltar reported considerable efforts in community and organizational engagement.

Team Europe selected Netherlands, Belgium, and Switzerland (high-trust environments). These countries ranked very high on public trust surveys, and the team wanted to determine which dimensions contributed to this high trust. In addition, Netherlands boasts some of the strongest relationships among police and the academic community, and this afforded the study team with opportunities to interact with others keenly interested and well informed in the research theme. In the case of Belgium, re-earning public trust has been a major focus since significant issues arose more than a decade ago. And in Switzerland, the team was interested to see how that country's restrictive stance on immigration may be affecting public perceptions and confidence.

Team Scandinavia selected Norway, Sweden, and Finland (highest-trust environments). The literature consistently supports a common impression that these nations enjoy some of the greatest harmony among police and an increasingly diverse social order, yet policing styles (e.g., armed vs. unarmed) and levels of diversity (e.g., Finland vs. Sweden) vary to a considerable degree. In addition, prior Global Studies cohorts have observed the deep and evident commitment in these countries to community engaged models of policing, and the team was interested in learning more about possible correlations to trust.

Across the 15 countries visited, over 50 formal meetings were held. These formal, hosted interviews included various police agencies and specific departments, other ministries, non-governmental organizations (NGO's), Ambassadors and High Commissioners and their staffs, local academics, and local or international media sources. Most were held at the various organizations' headquarters. Although the interview questions were structured in advance, in many cases the interviewees had prepared presentations and the researchers had to insert the consistent questions during conversation. At each meeting, a member of the research team took detailed notes and these were analyzed, themed, and documented almost daily. These field journal notes were also shared across all teams via the interactive forum provided within the Global Studies program. 
Excellent qualitative information was also obtained from the many impromptu, unscheduled interviews with the public in every country studied, bringing the total number of interview sources to over 100. Teams interviewed taxi drivers, private drivers, business owners and workers, and individuals on buses, planes, and in local cafes.

Due to the narrative form of the data captured from all interviews, and a commitment to respondent and host-country confidentiality as set out in the team's research model, specific data are not shared outside of the program. Suffice to say that the researchers were challenged to distill meaning and insights from the notes and journals of all 20 members of the team, and this was accomplished through a sequence of subteam presentations and full team discussions of the field data during workshops that followed their return to Canada. This process soon revealed many consistent observations when data were considered against the original dimensions and the interview framework. Evident patterns emerged where characteristics of the policing context, local police practices, and public perceptions of those practices were notable for their contributions to higher trust environments, and conversely, where low trust patterns were explained and supported by the interview data and other local source materials.

Several recurrent themes were captured in this process, using codes and categories built upon the dimensions identified earlier by the research team. Some of these would ultimately serve as the basis for practical recommendations for future consideration in Canada. Others went deeper to the core of public trust as a social construct.

Interpretive inquiry was applied in this study, a qualitative method that enables researchers to trace linkages in their narrative research findings to establish valid associations between human beliefs and exhibited behaviour, and to achieve 'thick' appreciations of lived experience (Neuman, 2006). To be truly insightful, such inquiries must get to "the sidestreets, backyards, and cabarets" (Welton, 1987, p. 66), as was done by all sub-teams in this study. Through such methods, interpretive researchers are able to delve deeply into the apparent attitudes and perceptions of people in order to induce meaningful new grounded theory about the nature of their experience (Neuman, 2006).

As a result, several of the deeper emerging themes began to take on a definitive new shape for the team and became recognized as recurrent underpinnings essential to trusted relationships. These themes led, in turn, to the team's conception and expression of a new grounded-theory model-a genetic code of public trust-as further described below.

\section{RESULTS}

\section{"Trust arrives on foot but leaves on horseback" - Johan Thorbecke, c1860}

\section{Research Findings and a Call-To-Action}

The CACP Global Studies 2017 cohort was asked to define new measures of trust. Over the entire course of its research study, no definitive methods were uncovered other than the traditional public survey. Moreover, such surveys in wide use around the world vary mostly between 'public satisfaction' with the services delivered by police, and in rare cases, the perceived 'legitimacy' of the police. Very few actually target the issue of trust-in-the-police directly, and those that do are almost exclusive to Western Europe and Scandinavia (CACP Global, 2017a).

Thus, this research was unable to reveal a clear performance measurement methodology to demonstrate public trust in the police. And as such, neither can it confirm that public trust in the police within Canada is empirically heading either up or down. What it can confirm, based on a wide range of indicators, comparative global insights, and domestic observations, is that the Canadian policing community may indeed be at a crossroads as it pertains to public trust ... and that it would be wise for policy makers and police leaders to take action. The research results introduce to the Canadian policing community what the study team has characterized as the "Genetic Code of Public Trust" - expressed as seven principles of trusting and trusted relationships in general, derived from the full team synthesis of data following the field studies, that are directly and most certainly applicable among police and the communities they serve (CACP Global, 2017a).

The researchers assert that these seven principles of trust presented below, and recently delivered to the CACP Board of Directors in a separate summary report, collectively embody that genetic code of public trust, and that they constitute a new theoretical model that may help to define the overarching values that Canadian policing must adopt if public trust in the police is to be sustained in Canada.

\section{The Genetic Code of Public Trust in Policing}

Trust is Fragile: Trust must be nurtured and can never be taken for granted. It requires a long-term investment, and it can erode quickly and suddenly.

Trust is Reciprocal: Trust goes both ways. Trust is always a two-way relationship, and the public's trust in the police will be affected by the degree to which police actively and visibly demonstrate trust (or mistrust) in each and every community they serve.

Trust Cannot be Aggregated: Each individual in every community matters. Public trust cannot be understood or measured as a collective score. And, trust in the police must be understood as distinct from all other institutions and sectors.

Trust Derives from Peel's Mission: Policing by consent is a Canadian foundation. We must recognize and exhibit that our role is to serve the Charter, with the Criminal Code as just one of many tools available to us. Trust occurs when our policing behaviours validate a community's hope that our interests and our mission will remain aligned with their goals and aspirations.

Trust Demands Validation: Trust cannot be measured in subjective isolation; evidence of trust (or mistrust) must be understood from multiple perspectives.

Trust Demands Transparency: Information must be open by default, and restricted only when there is a valid and openlyexplained reason.

Trust Demands Accountability: Policing must be seen to celebrate, invite, and welcome public accountability in all its forms. 
Embedding these principles into the codes of ethics for every police organization, and into the early training of every police officer and civilian member, may constitute a primary step to ensuring Canadian police services are truly fostering a culture that will build and sustain public trust. While certainly not easy, the team asserts that building trusted relationships with Canadians might be a lot less complicated than some may think (CACP Global, 2017a). Each serving police member has the ability to give effect to the above principles, and in fact, all of us in general have the necessary experience. As these principles came into focus during the research, the study team discovered that we all apply these methods in our daily lives and in our most important personal relationships.

As outlined below in the team's seven calls-to-action, also included in the final report to the CACP, the team believes that all police services individually and collectively across the country can also apply the principles in practical ways within a policing environment to elicit and sustain the trust of their public. Founded in the above noted principles, the team has recommended these practices to depict the trustbuilding steps that they believe police at all levels, from the individual to the local to the national, may elect to embrace and put into action (CACP Global, 2017a).

\section{Trust Building Practices: A Call-to-Action for Canadian Policing}

Note: The team's summary report to the CACP includes a Table that converts each of these 'calls-to-action' into greater detail, and shows examples of how each can be applied at the level of the individual police member (sworn or civilian); at the local or provincial police service; and at a national level of police leadership (CACP Global, 2017a).

Engage Each and Every Community: Community engagement is everyone's responsibility. It is not a program or simply an expressed philosophy, but it must be evident as our way of doing business. It is a core responsibility of all police officers and civilian staff members to ensure inclusion and engagement of all members of society in each diversely self-identified 'community' we serve. Every interaction must be recognized as an opportunity to build trust.

Relate Independently: Police must be seen as independent from government, other sectors, and politics. Police must remain impartial and focused on our core policing mandates. Police must take responsibility for their relationships with the communities they serve.

Embrace Accountability: Policing agencies must ensure 'visible' accountability in all aspects of service delivery and member conduct, via both internal and external processes. As the police, we are accountable to all Canadians in everything we do.

Professionalize Relentlessly: This calls for shared standards, as much as is attainable across all policing jurisdictions in Canada, and must include both our social skills and our technical competencies, in both our theoretical knowledge and in our practical application. The foundation of trust is established by the pursuit and daily evidence of a national level of professionalism, reflective of pan-Canadian community values and expectations.

Liberate Information: Accessibility and timeliness of information has become an expectation of the public. Withholding information will undermine trust. We must continue to learn what information is meaningful and most important to our communities. Our default position must be to liberate that information except where prohibited, and any such restrictions must be clearly and openly conveyed.

Employ a Mutual Trust Dashboard: All police services should strive to consistently develop and apply mixed method and community-engaged approaches to gain an accurate and continuing measure of trust. Services must work with their community to establish meaningful methods and measures, and proactively share outcomes on a frequent basis.

Celebrate Canadian Policing: All agencies and members must promote a positive Canadian policing identity that reflects the values of our communities, reinforces who we are and what we stand for, and conveys what the public should expect from their police. Public trust will only be achieved and sustained when every Canadian can recognize and believe us in this simple expression: "Canada ... We Are YOUR police."

\section{DISCUSSION}

$$
\begin{gathered}
\text { "To say we trust you means we believe you have the } \\
\text { right intentions toward us and that you are } \\
\text { competent to do what we trust you to do" } \\
\text { - Hardin, } 2006
\end{gathered}
$$

\section{Implications for Public Policy and Practice}

The CACP has always encouraged its Global Studies cohorts to be mindful of the highly practical and action-oriented nature of police culture in crafting their final deliverables. Thus, in adopting the genetic code language and related imagery that has shaped the team's primary research products (CACP Global, 2017b) (see Figure 1), the team hoped to distill some rather complex ideas into a framework that is elegantly simple in its expression. However, the team is also fully aware that there is a distinct difference between simple and easy. The recommended practices also outlined in the research results may indeed challenge the prevailing culture, attitudes, and day-to-day behaviours of police at every level of the system.

Police services and their governing boards, and even the Canadian Centre for Justice Statistics, remain heavily invested in the regular execution of public satisfaction surveys, even while efforts continue to better refine those instruments, albeit mostly from a police-centric lens to date. ${ }^{1}$ Police Act legislation across Canada has paid scant attention to the issues of public trust, instead, to cite one provincial example, focusing adequacy requirements on requiring police services to develop a three-year business plan that establishes "quantitative and qualitative performance objectives and indicators relating to ... (ii) community satisfaction

Public Safety Canada and POLIS have recently initiated in a pilot study a set of questions designed to capture core indicators for public attitudes toward police. 


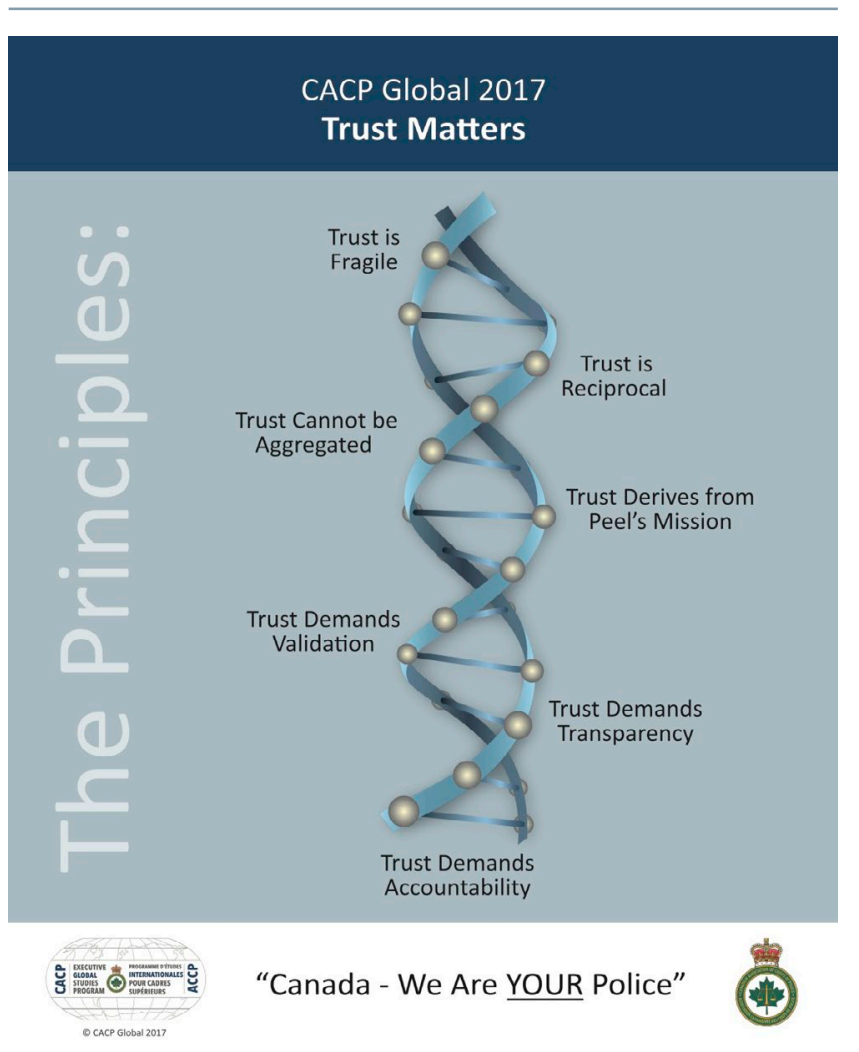

FIGURE 1 Genetic code of public trust principles

with police services" (Government of Ontario, 1999). The resulting tendency to aggregate, publish, and compare scores derived from these methods, in the view of the research team, may be an insufficient way to understand the levels of trust among select communities. Such a practice may also serve to insult and further marginalize those groups whose attitudes and aspirations are not fairly reflected in those positive, yet aggregated, satisfaction scores in the first place.

The Global Studies principles and practices amount to a call for a much more community-engaged approach, and one that is more qualitative than quantitative by design, anchored in rich, recurring, and meaningful conversations among community members and the police members who are there to serve their community safety and well-being (CSWB) needs. Such an approach could align nicely with other CSWB developments underway across Canada, in which police are increasingly adopting a greater balance between their enforcement and suppression roles, and their preventive and early intervention roles performed as just one part of a broader human services system (Hawkes, 2016; McFee \& Taylor, 2014; Nilson, 2017).

With regard to metrics of public trust, the research team believes there is an opportunity to craft entirely new language and new models for this, with an emphasis on multiple measures, supported by diverse indicators, and derived mutually among shared community, police, and public policy perspectives.

With reference to their phrasing in one of their recommended practices, "Professionalize Relentlessly", the team is signaling that the only public trust that matters will be one that is consistently earned and deserved. In other words, policing must continue and expand upon its broad-based commitments to evidence-based practices, and continue to raise its own internal bars with regard to both the technical and social competencies required to meet the needs of a modern, globalized, diverse, and technology-rich society (CACP Global, 2016). By reference to some of the higher-trust countries that formed part of these studies, Canadian policing remains comparatively more heavily rooted in a paramilitary model of recruit attraction, selection, and training (CACP Global, 2016, p10).

Finally, one of the greatest challenges any of us faces is to acquire the correct balance of confidence and humility necessary to both welcome and respond appropriately to being held accountable for our decisions and our actions. Police boards and governing authorities, in particular, will want to pay close attention to the team's recommendations in these areas, and to ensure that the initial responses by police services to questions, complaints, and information requests from the public - and from the institutional and social media-do not transmit a defensive and closed-system attitude.

\section{Strengths, Limitations, and Future Research Directions}

As noted from the outset of this paper, this research arose from a bounded program of study for executives and, as such, occurred within strict limits of time, resources, and scope. The Global 2017 team recognized these boundaries throughout and sought to position their results as a form of conversation starter, rather than as any sort of definitive closing argument. Success, they decided early on, would be reflected in the degree of uptake and continuing attention to the issues they would hopefully help to illuminate in new ways and with new ideas for understanding the problems and their potential solutions.

An immediate measure of this took shape just recently, only two months following the release of the team's research findings, when the CACP Board hosted an invitational thinktank session devoted to further exploration of the team's genetic code concepts and their related, proposed actions. As one result from the session, the CACP President has called for the continuing generation of a new 'road map to public trust' across Canadian policing (Taylor, 2017). As another, a new research community has been formed within the CACP'S research portal, to stimulate further exchange of ideas, published evidence, and relevant studies.

This work also seems to have ignited considerable interest beyond Canada. The team's work was presented at the recent International Association of Chiefs of Police [IACP] conference in Philadelphia, resulting in expressions of further interest from several countries in attendance, and some very positive conversations about the novel way that the research has been conveyed under the genetic code construct. The authors remain optimistic that such conversations will continue to advance wider interest and genuine attention to the specific issue of public trust in the police, a truly global concern.

\section{CONCLUSIONS}

From a 15-country global field study, combined with domestic and US research, the CACP Global 2017 cohort has learned that Canadian policing is very well respected, often envied around the world, and undoubtedly doing many things 
right. Comparatively to many nations, the Canadian policing community may be in better shape than many with respect to the trust it enjoys from its public, in generalized terms. However, given the rapid changes and socio-economic and political influences upon an already diverse society, Canadian policing may soon be facing a crossroads.

The research has identified seven principles that may more accurately capture and express the genetic code of trusted relationships. The integration of these principles into Canadian policing culture can perhaps set a new foundation from which to advance public trust in the police. Further, the broad and consistent execution of several calls-to-action, at all levels within the policing community, will entrench a visible commitment to trust-building and continuous self-improvement within Canadian policing, now and into the future.

The research team observes that nowhere in the world does everyone trust the police, and in some countries virtually no one does. Yet, there was always one key group the teams encountered who consistently reported a perception of high trust in the police-that group was the police agencies themselves. Generally speaking, police worldwide appear to have an overly positive perception of how the public trusts them, and this may indeed be just as true in Canada, where aggregated satisfaction scores serve as a primary, but flawed, proxy for gauging public trust.

The research team would assert that police everywhere, and their stakeholders at all levels of the system, may need to listen much more closely to each and every community they serve.

\section{ACKNOWLEDGMENTS}

The authors extend their appreciation and recognition to the other 17 members of the CACP Executive Global Studies 2017 cohort for their contributions to this work, to the Board of Directors and staff of the Canadian Association of Chiefs of Police for their support and guidance throughout, and to the RCMP International Liaison Officers and the Ontario Provincial Police Eric Silk Library for their research assistance.

\section{CONFLICT OF INTEREST DISCLOSURES}

One of the co-authors of this paper, Norman E. Taylor, serves as Editor-in-Chief of the Journal of Community Safety and Well-being.

\section{AUTHOR AFFILIATIONS}

${ }^{*}$ Ontario Provincial Police, Orillia, $\mathrm{ON} ;{ }^{+}$Calgary Police Services, Calgary, AB; ${ }^{\ddagger}$ Canadian Armed Forces; $\$$ Community Safety Knowledge Alliance, Saskatoon, SK, Canada.

\section{REFERENCES}

Awan, S. (2014). Rebuilding trust in community colleges through leadership, emotional healing, and participatory governance. Community College Enterprise, 20(2), 1-12

Blind, P.K. (2006). Building trust in government in the twenty-first century: Review of literature and emerging issues. UNDESA 7th Global Forum on Reinventing Government, 26-29 June 2007, Vienna. New York, NY: United Nations Dept. of Economic \& Social Affairs (UNDESA).

Boda, Z., \& Medve-Balint, G. (2017). How perception and personal contact matter: the individual determinants of trust in police in Hungary. Policing \& Society, 27(7), 732-749. Epub August 2015

Bradford, B., Martin, R., García Añón, J., Gascón Cuenca, A., García Saez, J., \& Llorente Ferreres, A. (2016). Instrumental and affective influences on public trust and police legitimacy in Spain. European Journal of Policing Studies, 3(4):394-416
Brecher, R. W., \& Flynn, T. (2002). Principles of risk communication: Building trust and credibility with the public. In W. M. Haschek, C. G. Rousseaux, \& M. A. Wellig (eds.), Handbook of toxicologic pathalogy, Vol. 1. Cambridge, MA: Academic Press, 447-457.

CACP. (2006). Applying problem based learning and transformative leadership development to global research in policing and public safety. Kanata, ON: Canadian Association of Chiefs of Police. Retrieved October 29 2017 from http://www.cacpglobal.ca/index.php/executive-pbl

CACP Global. (2016). What happens there matters here ... but how? Summary report from CACP Global 2016 for the CACP Board of Directors. Kanata ON: Canadian Association of Chiefs of Police. Ottawa. P.10. Retrieved October 29, 2017 from http://www.cacpglobal.ca/images/pdf/ CACPGlobal2016SummaryReportToBoardofDirectors.pdf

CACP Global. (2017a). Trust Matters: An executive summary report for the Canadian Association of Chiefs of Police Board of Directors on the proceedings and outcomes of the 10th cohort. CACP Executive Global Studies Program. Ottawa, ON: CACP. Available at http://www. cacpglobal.ca/images/2017cohort/CACP_Global_Studies_2017_Summary_Report_-_Trust_Matters_July_18.pdf

CACP Global. (2017b). Trust matters: The principles. Info-graphic depicting the genetic code of public trust. CACP Executive Global Studies 2017. Kanata, ON: Canadian Association of Chiefs of Police. Available at https://www.google.ca/search?q=Trust+matters:+The+principles.+Info graphic+depicting+the+genetic+code+of+public+trust.\&tbm=isch\&tbo $=u \&$ source=univ\&sa=X\&ved=OahUKEwisl LDOv8PXAhWD5IMKHFFyB $D A Q_{s} A Q\|\| \& b i w=1280 \& b i h=627$

Chan, N. (2016). Strengthening the Royal Malaysian Police by enhancing accountability. Policy Ideas, No. 33. Kuala Lumpur, Malaysia: IDEAS.

Chan, N. (2017). Reigning in the IGP's power: Decentralisation as an option. Policy Ideas, No. 43. Kuala Lumpur, Malaysia: IDEAS

Cresswell, J. W. (2009). Research design: Qualitative quantitative and mixed method approaches (3rd edition). Thousand Oaks, CA: Sage.

Edelman, R. (2017). Edelman Trust Barometer: Annual Global Summary. Executive Summary. Chicago, IL: Edelman.

Goldsmith, A. (2005). Police reform and the problem of trust. Theoretical Criminology, 9(4), 443-470.

Government of Ontario. (1999). Adequacy and effectiveness of police services. Police Services Act: Regulation 3/99. Toronto, ON: Government of Ontario. Retrieved October 29, 2017 from https://www.ontario.ca/ laws/regulation/990003

Hawkes, J. V. N. (2016). Mobilizing and engaging your community to reduce victimization and reinvest police resources. Journal of Community Safety and Well Being, 1(2), 21-25.

Hidayat, L. (2016). Indonesia's police-has there been reform? Strategy Review: The Indonesian Journal of Leadership, Policy and World Affairs, JulySeptember. Available from: http://www.sr-indonesia.com/in-the-journal/ view/indonesia-s-police-has-there-been-reform

Kasher, A. (2003). Public trust in a military force. Journal of Military Ethics, $2(1), 20-45$

Kalra, S., Unnikrshnan, A. G., \& Baruah, M. (2017). Interaction, information, involvement (The 3I strategy): Rebuilding trust in the medical profession. Indian Journal of Edocrinology and Metabolism, 21(2), 268-270.

Latusek, D., \& Oleiniczak, T. (2016). Development of trust in low-trust societies, Polish Sociological Review, 195(3), 1231-1413.

Lawrence, A. (2017). Measuring the public's views on their police service. Presentation to CACP Executive Global Studies Program February 28 2017. Ottawa, ON: Public Safety Canada.

Maguire, S. (2017). Measuring community trust in police. Presentation to CACP Executive Global Studies Program February 29 2017. Ottawa, $\mathrm{ON}$ : Carleton University.

McFee, D. R. \& Taylor, N.E. (2014). The Prince Albert hub and the emergence of collaborative risk-driven community safety. Change and Innovation in Canadian Police Series. Ottawa, ON: Canadian Police College. 
Mezirow, J. (1991). Transformative dimensions of adult learning. Hoboken, NJ: Wiley \& Sons, Inc.

Misztal, B. A. (1996). Trust in modern societies: The search for the bases of social order. New York, NY: Polity Press.

Murphy, K., Mazerolle, L., \& Bennett, S. (2014). Promotion trust in police: findings from a randomised experimental field trail of procedural justice policing. Policing and Society, 24(4), 405-424.

Neuman, W. L. (2006). Social research methods: Qualitative and quantitative approaches (6th edition). Boston, MA: Pearson Education Inc.

Nilson, C. R. (2017). Mobilizing the CSWB measurement community: Reflections from the Interactive National Dialogue on Research, Evaluation and Analysis of Hub/Situation Tables in Canada. Journal of Community Safety and Well Being 2(2), 63-65.

OECD. (2017). Trust and public policy. How better governance can help rebuild public trust. Paris, France: OECD. Retrieved October 28, 2017, from OECD: http://www.oecd.org/gov/trust-and-public-policy9789264268920-en.htm

OSAC. (2016). Spain 2016 crime \& safety report. Washington, DC: Bureau of Diplomatic Security. Retrieved March 15, 2017, from: https://www. osac.gov/pages/ContentReportDetails.aspx?cid=19045
Sahapattana, P. \& Cobkit, S. (2016). The relationships between police performance and public confidence: a case study of Thailand. Police Practice and Research, 17(2), 171-182.

Sunshine, J. \& Tyler, T.R. (2003). The role of procedural justice and legitimacy in shaping public support for the police. Law \& Society Review 37(3), 513-548.

Taylor, L. (2017). Trust matters: An invitational discussion among police leaders from across Canada. Kanata, ON: Canadian Association of Chiefs of Police. Retrieved October 29, 2017 from https://rfconnect.cacp.ca/ home [member forum requires sign-in].

The Local Es. (2017 January 17). "Spain is still one of the most corrupt countries". (2017, January 17). The Local Es. Retrieved March 15, 2017, from https:// www.thelocal.es/20170125/spain-corruption-transparency-international

Tonkiss, F., Passey, A. Fenton, N. \& Hems, L. C. (2000). Trust in civil society. London, UK: Palgrave Macmillan.

Welton, M. R. (1987). 'Vivisecting the nightingale': Reflections on adult education as an object of study. Studies in the Education of Adults, 19(1), 66 


\section{APPENDICES}

\section{Appendix A: Research Dimensions Definitions}

Sociopolitical: social, economic and political context that defines, shapes, and influences the demands made of police

Economic state

- Political structure

- Judicial system

- Human rights

Legal Framework

- Demographics

Immigration

Education

- Community (public) mental health and social support programming

- Corruption

Policing framework: structure underlying the delivery of policing services and programs
- Style of policing
- Budget/resourcing
- Composition \& \#s
- Use of force
- Intelligence model

Information Management: discipline that directs, supports and effectively and efficiently shares and manages data/metrics - Open data \& info sharing

- Metrics/analytics

- Technology \& equipment

- Digital evidence management

- Security \& privacy

Engagement/Communication: clear, consistent messaging of pertinent information via a variety of methods; the interactions, behaviours, and relationships to encourage participation/collaboration

- Traditional \& social media

- Consultation \& collaboration at all levels

- Proactive/reactive communication strategy

Professionalism \& Competence: organizational values, specialized knowledge, attitudes, skills, and abilities associated with policing

- Training

- Unionization

- Recruitment

- Diversity

- Standards, codes, values, mission

- Member health, commitment, and behaviour

- Add autonomy and discretion

Integrity

Accountability: responsibility for actions, products, decisions, and policies

- Oversight internal/external

- Perception of management

- Conduct \& discipline

- Transparency

- Fiscal accountability 


\section{Appendix B: Interview Questions}

\section{General Questions}

What do you think will have the biggest impact on policing in the next 5 years?

What is an ideal trusting relationship look like?

What leads people to trust or distrust police?

How important is trust to policing?

What indicates to you that trust is changing?

How has your police organization change over the last (25) years?

What are the police doing to maintain your trust in them?

What are you doing to maintain the trust in your community?

\section{Sociopolitical}

What are some of sociopolitical influences (factors) that are impact/affecting trust in policing in your country?

Have these factors changed recently?

\section{Policing Framework}

Tell us about your policing organization/structure - how has your organization evolved?

How would you describe your style of policing and how would it impact trust?

What changes would improve your policing framework?

Do you feel that police are properly resourced to effectively create/maintain trust?

\section{Information Management}

How do you manage and share information in your police organization/and community? Is this managed via technology?

Tell us about your police technological resources? Are they sufficient?

What police information is shared - is this effective?

What freedom of information policies exist within your organization

Do you have established criteria to determine trust with (employees, public)?

- How do you measure it (surveys, frequency)?

\section{Engagement \& Communication}

Tell us how you engage and communicate with your community and with your organization?

- How do you use social media to engage/communicate with community/organization? And, to what degree does social media impact your decision making?

Do you feel engaged with your policing organization?

Did you have difficulty in capturing information from the respondents on police trust?

How is the media influenced by the government (vice versa)?

\section{Professionalism \& Competence}

Tell us about the characteristics and competencies you expect of a police officer. Do the police officers in your community exhibit these attributes (13 behaviours of high trust)

How do you hire police officers? What training do they receive?

Is your organization a reflection of the community? If so, how does this impact trust?

Do your policing leaders set policing missions, visions conduct - how do they ensure these standards are being followed? Do these reflect public expectations?

\section{Accountability}

(Why) is accountability important to your policing organization?

In what matters are police held accountable? (Threshold)

What can you tell us about accountability processes as they relate to policing? (oversight)

What if any changes would you make to the accountability process(s)? 